\title{
The Trend of Women's Autonomy in Refusing Risky Sex and Associated Factors in Ethiopia: Evidence From 2011 \& 2016 EDHS Data
}

Melkamu Dires Asabu ( $\sim$ ketera2019@gmail.com )

Woldia University

\section{Research Article}

Keywords: Autonomy, Ethiopia, Refusing, Risky Sex, Women

Posted Date: February 22nd, 2021

DOI: https://doi.org/10.21203/rs.3.rs-208952/v1

License: (c) (1) This work is licensed under a Creative Commons Attribution 4.0 International License.

Read Full License 


\section{Abstract}

Background: Risky sexual behavior is a major public health concern of Ethiopians. Although studying the autonomy of women in refusing risky sex is significant to take proper actions, the issue is not yet studied. Accordingly, this population-based nationwide study was aimed at assessing the trends of women's autonomy in refusing risky sex and its associated factors in Ethiopia.

Method: The sample was limited to married women of $2011(n=8369)$ and $2016(n=8403)$ Ethiopian Demographic and Health Survey (EDHS) data. Women's autonomy in refusing risky sex was measured based on wives' response to 'not having sex because of husbands have other women. To examine associated factors, sociodemographic variables were computed using binary logistic regression.

Result: The finding revealed that the trend of women's autonomy in refusing risky sex had declined from $78.9 \%$ in 2011 to $69.5 \%$ in 2016 . Women aged from $25-34$ were less likely autonomous in refusing sex (AOR $=.764 ; 95 \% \mathrm{Cl}=.605, .965)$, in comparison with women aged less than 24 years old. The autonomy of women with primary, secondary, and higher educational status were $\mathrm{AOR}=1.607 ; 95 \% \mathrm{Cl}: 1.379,1.874$, AOR $=2.208 ; 95 \% \mathrm{Cl}: 1.639,2.975$, and $\mathrm{AOR}=3.221 ; 95 \% \mathrm{Cl}: 1.647,6.300$ respectively. The autonomy of women from rich households was more likely higher $(\mathrm{AOR}=1.523 ; 95 \% \mathrm{Cl}: 1.28,1.813)$ in comparison to women from poor households. The autonomy of women in Tigray, (AOR=2.938;95\%Cl:2.025,4.263), Afar (AOR=1.497;95\%Cl:1.111,2.017), Amhara (AOR=4.870;95\%Cl:3.388,7.000), Benishangul Gumuz $(\mathrm{AOR}=.568 ; 95 \% \mathrm{Cl}: .406, .796)$, SNNP (AOR=1.900;95\%Cl:1.355,2.664), Harari (AOR=.516;95\%Cl:.372,.716), and Addis Ababa $(A O R=3.809 ; 95 \% \mathrm{Cl}: 2.227,6.516)$ when compared with autonomy of women who resides Dire Dawa.

Conclusion: The autonomy of women in refusing risky sex has declined from 2011 to 2016 . This infers that currently, women are more victimized than previously. Hence, possible interventions like empowering women shall be taken to protect women from certain health problems of risky sexual behavior.

\section{Introduction}

Risky sexual behavior is defined as an individual's practice in one or more of the following acts such as unprotected sexual intercourse, starting sexual activity at a young age, having multiple sexual partners, having sex under the influence of stimulant substances, or having sex immediately after watching pornographic (1-4). Risky sexual behavior is a major public health concern across the world but the issue is more serious in developing countries including Ethiopia. It increases the likelihood of individuals' vulnerability in sexually transmitted infections (STIs), HIV/AIDS, unwanted pregnancy, and psychological distress (5).

Having multiple sexual partners refers that an individual's sexual interaction with two or more sexual partners that overlapped in time (6). Since having multiple sexual partners is risky sexual behavior and a key driver of HIV/AIDS transmission, those who have concurrent sexual partners increase their risk of contracting HIV/AIDS. Moreover, actors of multiple sexual partners are more likely exposed to sexually 
transmitted infections (STIs). Thus, since having multiple sexual partners is risky sex, measures not to have sexual intercourse with those who have multiple sexual partners can be understood as a refusal of risky sex.

Autonomy can be defined as a technical, social-psychological ability of an individual for making decisions about his/her private concerns (7). An individual is autonomous when she/he can act under her/his direction, i.e. make her/his actions (8). Autonomous women can refuse risky sex if husbands have risky sexual behavior like having sexual contact with an additional woman. This is to protect themselves from adverse effects of risky sexual behavior like sexually transmitted infections (STIs) and HIV/AIDS. Concerning women's autonomy, research and policy discourse indicated the presence of limited autonomy of women in developing countries and also the challenge of their lower autonomy to improve their reproductive health $(9,10)$.

In Ethiopia, the magnitude of risky sexual behavior particularly in having multiple sexual partners estimated up to $53.7 \%$ (11). Understanding the trend of women's autonomy and associated factors in refusing risky sex is necessary to take possible interventions like empowering women and minimize the risk of sexually transmitted diseases due to multiple sexual partners. However, the trend of women's autonomy and its associated factors in refusing risky sex is overlooked by researchers in Ethiopia. Thus, this study was focused on examining the trends of women's autonomy in refusing risky sex and its associated factors in Ethiopia. Since the study was completed using the 2011 and 2016 Ethiopian DHS data, the finding will help to understand the trends of women's autonomy from time to time in one hand, and since associated factors were identified, it is also important to take proper intervention for women health on the other hand.

\section{Objectives Of The Study}

The study's objectives were: To examine the trends of women's autonomy in refusing risky sex in Ethiopia using 2011 \& 2016 EDHS data and to identify determinants factors of women's autonomy in refusing risky sex in Ethiopia.

\section{Methods}

\subsection{Study Design and Data Collection}

It is a population-based cross-sectional study design based on the 2011 and 2016 EDHS data. The study used data from the 2011 and 2016 EDHS that were collected by the Central Statistical Authority (CSA) of Ethiopia and Opinion Research Corporation Company (ORC) Macro International. It was conducted in all Regional States of Ethiopia namely Tigray, Afar, Amhara, Oromia, Somali, Benishangul Gumuz, Southern Nations Nationalities and Peoples (SNNP), Gambella, and Harari and Addis Ababa, and Dire Dawa city Administrations (CSA and ICF, 2016) (12). It is a nationally representative sample survey, aged 15-49 years' women. 
The survey collected a detailed woman's background characteristics. The survey also collected information from unmarried, married, living with a partner, divorced, and widowed women. However, for this study, the researcher has used only married women's data. Based on the valid number of responses for identified variables, the sample size of the study from 2011 and 2016 DHS data was limited to 8369 and 8403 respectively.

\subsection{Variables and Measurement}

\section{Dependent Variable}

The study's dependent variable was women's autonomy in refusing risky sex. This was measured based on women's response on 'Reason for not having sex because of husbands have other women'. Wives who can refuse sex if husbands have other women were considered as 'autonomous in refusing risky sex' and wives who cannot refuse sex if husbands have other women were considered as 'not autonomous in refusing risky sex'. Finally, the dependent variable that dichotomized as "autonomous in refusing risky sex', and 'not autonomous in refusing risky sex' was coded as " 0 " and " 1 " respectively

\section{Independent Variables}

The study identified the following independent variables including women's age, education status, working status, place of residence, household wealth index, religion, and region. The researcher adopted the measurements of the DHS survey for the following four independent variables. However, the measurements of the DHS survey on the following variables including age, education level, and household wealth index were adapted as follows.

The adapted measurements include (1) age of respondents that was open to writing their exact age, but the study that focused on modern contraceptive use measured age of label age of respondents by labeling from aged 15-24, 25-34, and 35-49 (13). Since there are few women in marriage since the age of 11 , this study used 11-24, 25-34, and 35-49 age categories of women. (2) For educational attainment, the DHS used six responses such as no education, incomplete primary, primary, incomplete secondary, secondary, and higher. As studies were done using DHS data on "the effect of maternal health service utilization in early initiation of breastfeeding among Nepalese mothers" (14). as well as "women empowerment and their reproductive behavior among currently married women in Ethiopia" (4) have used 'illiterate', 'primary', 'secondary' and 'higher' to measure this variable, for this study, incomplete primary and primary, and incomplete secondary and secondary merged into 'primary' and 'secondary' respectively. (3) Concerning the wealth index, the middle was taken as it is but the categories poorest and poor, and rich and richest were merged into poor and rich respectively. Other studies (15-18) have also used these variables to measure the wealth index.

\subsection{Data Analysis}


The data obtained from 2011 and 2016 EDHS were analyzed through SPSS version 22 in three levels. First, the univariate/descriptive statistics were used to summarize the socio-demographic variables of the study participants using frequency and percentages. Second, the bivariate analysis was done using the chi-square test $(p<0.05)$ to identify the socio-demographic variables that were significantly associated with women's autonomy in refusing risky sex. Finally, analysis of the determinants of women's autonomy in refusing risky sex was carried out using logistic regression. This is because logistic regression is used to examine the relationships between a categorical outcome variable and one or more categorical or continuous predictor variables (19). Principally, binary logistic regression is applied in cases where the dependent variable is dichotomous (20). This is because the dependent variable (women autonomy in refusing risky sex) was dichotomized as "not autonomous in refusing risky sex" and "autonomous in refusing risky sex".

For binary logistic regression analyses, statistical inferences were made based on estimates of the odds ratio (OR) with a $95 \%$ confidence level and $5 \%$ margin of error or p-value less than 0.05 . The study used an unadjusted odds ratio to estimate the gross effect of each independent variable on the outcome variable. The independent variables that had an association of a p-value less than 0.05 with the outcome variable were taken for the multiple or adjusted analysis.

Before reporting the result of the adjusted odds ratio, the overall goodness of fit was assessed via the Hosmer-Lemeshow test. The result of this analysis's P-value (0.606) was greater than the level of significance $a=0.05$, hence data fit the model well. Because in the Hosmer-Lemeshow test, an insignificant chi-square indicates a good fit to the data (Hosmer \& Lemeshow, 2000).

\section{Results}

As we have seen in figure 1, the autonomy of women in refusing risky sex has declined from $78.9 \%$ in 2011 to $69.5 \%$ in 2016 .

As it has shown in Table 1, the percentage of autonomous women refusing risky sex in 2011 was $78.9 \%$, while in 2016 it has declined to $69.5 \%$. There is a significant decrement of women's autonomy in refusing risky sex. When the age of women and their autonomy in refusing risky sex directly associated in 2011 but there is up and down in 2016. Women's educational status and their autonomy in refusing risky sex were directly associated in both 2011 and 2016. In both 2011 and 2016, the autonomy of employed women in refusing risky sex was better than housewife/unemployed women albeit its percentage is not identical. Regarding residence, the percentage of rural women autonomous in refusing risky sex was $89.6 \%$ and $79.8 \%$ in 2011 and 2016 were respectively. Similar to the educational status of women, in both 2011 and 2016, the numbers of autonomous women refusing risky sex increased from poor to rich wealth index.

In terms of religion, in 2011 the top three autonomous women in refusing risky sex were Orthodox Christian (87.8\%), Muslim (74.4\%), and Protestant Christian (73.8\%) women, but the top three 
autonomous women in refusing risky sex in 2016 were Orthodox Christian women (82.3\%), women from others religion (74.0\%) and Protestant Christian women (70.7\%).

Less performed women in refusing risky sex were women from other religions (61.3\%) and women from the traditional religion (64.6\%) in 2011 and 2016 respectively. In the case of geographic areas or regions, the top three autonomous women in refusing risky sex were found in Addis Ababa (95.3\%), Tigray (89.2\%), and Amhara (88.3\%) in 2011. In 2016, the top three autonomous women refusing risky sex were found in Addis Ababa (93.6\%), Amhara (89.1\%), and Tigray (85.6\%). Fewer performance women autonomy in refusing risky sex was recorded from Gambela (61.9\%) and Harari (53.7\%) regional states' women in 2011 and 2016 respectively.

Table 1: Description of Socio-Demographic Variables of Married Women 


\begin{tabular}{|c|c|c|c|c|c|}
\hline \multirow{2}{*}{\multicolumn{2}{|c|}{$\begin{array}{l}\text { Background Characteristics of } \\
\text { Women }\end{array}$}} & \multicolumn{4}{|c|}{ Women Autonomy in Refusing Risky Sex } \\
\hline & & \multicolumn{2}{|l|}{$2011 n=8369$} & \multicolumn{2}{|l|}{$2016 n=8403$} \\
\hline & & $\begin{array}{l}\text { Not } \\
\text { autonomous }\end{array}$ & Autonomous & $\begin{array}{l}\text { Not } \\
\text { autonomous }\end{array}$ & Autonomous \\
\hline \multirow[t]{3}{*}{ Age } & $<24$ & 1646(21.3\%) & $6085(78.7 \%)$ & $2370(30.7 \%$ & $5356(69.3 \%)$ \\
\hline & $25-34$ & $121(19.5 \%)$ & $499(80.5 \%)$ & $190(28.7 \%)$ & $473(71.3 \%)$ \\
\hline & $35-49$ & $3(16.7 \%)$ & 15(83.3\%) & $5(35.7 \%)$ & $9(64.3 \%)$ \\
\hline \multirow{4}{*}{$\begin{array}{l}\text { Educational } \\
\text { status }\end{array}$} & No education & $1405(24.7 \%)$ & $4275(75.3 \%)$ & $1857(36.2 \%)$ & $3269(63.8 \%)$ \\
\hline & Primary & $330(16.0 \%)$ & $1732(84.0 \%)$ & $537(24.4 \%)$ & $1667(75.6 \%)$ \\
\hline & Secondary & $28(7.2 \%)$ & $359(92.8 \%)$ & $123(18.1 \%)$ & $555(81.9 \%)$ \\
\hline & Higher & $7(2.9 \%)$ & 233(97.1\%) & $48(12.2 \%)$ & $347(87.8 \%)$ \\
\hline \multirow{2}{*}{$\begin{array}{l}\text { Working } \\
\text { status }\end{array}$} & Housewife & $1321(23.2 \%)$ & $4361(76.8 \%)$ & $1805(31.7 \%)$ & $3892(68.3 \%)$ \\
\hline & Employed & $449(16.7 \%)$ & 2238(83.3\%) & $760(28.1 \%)$ & 1946(71.9\%) \\
\hline \multirow[t]{2}{*}{ Residence } & Urban & $189(10.4 \%)$ & 1637(89.6\%) & $399(20.2 \%)$ & $1577(79.8 \%)$ \\
\hline & Rural & $1581(24.2 \%)$ & 4962(75.8\%) & 2166(33.7\%) & $4261(66.3 \%)$ \\
\hline \multirow[t]{3}{*}{ Wealth Index } & Poor & 1046(28.2\%) & $2659(71.8 \%)$ & 1465(38.5\%) & $2338(61.5 \%)$ \\
\hline & Middle & 265(19.9\%) & 1068(80.1\%) & $360(29.8 \%)$ & $847(70.2 \%)$ \\
\hline & Rich & $459(13.8 \% 0$ & $2872(86.2 \%)$ & $740(21.8 \%)$ & $2653(78.2 \%)$ \\
\hline \multirow[t]{6}{*}{ Religion } & Orthodox & $366(12.2 \%)$ & $2643(87.8 \%)$ & $529(17.7 \%)$ & $2454(82.3 \%)$ \\
\hline & Catholic & $29(33.3 \%)$ & $58(66.7 \%)$ & 15(30.6\%) & $34(69.4 \%)$ \\
\hline & Protestant & $387(26.2 \%)$ & 1089(73.8\%) & $466(29.3 \%)$ & $1126(70.7 \%)$ \\
\hline & Muslim & $937(25.6 \%)$ & $2728(74.4 \%)$ & $1519(41.5 \%)$ & $2145(58.5 \%)$ \\
\hline & Traditional & $22(38.6 \%)$ & $35(61.4 \%)$ & $23(35.4 \%)$ & $42(64.6 \%)$ \\
\hline & Others & $29(38.7 \%)$ & $46(61.3 \%)$ & $13(26.0 \%)$ & $37(74.0 \%)$ \\
\hline \multirow[t]{5}{*}{ Region } & Tigray & $93(10.8 \%)$ & 766(89.2\%) & $120(14.4 \%)$ & 711(85.6\%) \\
\hline & Afar & $303(38.7 \%)$ & $480(61.3 \%)$ & $244(34.8 \%)$ & $458(65.2 \%)$ \\
\hline & Amhara & 131(11.7\%) & $984(88.3 \%)$ & 107(10.9\%) & $879(89.1 \%)$ \\
\hline & Oromia & $220(17.9 \%)$ & 1011(82.1\%) & $490(41.6 \%)$ & $688(58.4 \%)$ \\
\hline & Somali & $176(31.8 \%)$ & $378(68.2 \%)$ & $385(49.5 \%)$ & $392(50.5 \%)$ \\
\hline
\end{tabular}




\begin{tabular}{|lllll|}
$\begin{array}{l}\text { Benishangul } \\
\text { Gumuz }\end{array}$ & $201(26.1 \%)$ & $568(73.9 \%)$ & $353(49.5 \%)$ & $360(50.5 \%)$ \\
\hline SNNP & $264(25.6 \%)$ & $769(74.4 \%)$ & $255(22.7 \%)$ & $869(77.3 \%)$ \\
\hline Gambela & $217(38.1 \%)$ & $353(61.9 \%)$ & $184(31.0 \%)$ & $409(69.0 \%)$ \\
\hline Harari & $83(15.9 \%)$ & $438(84.1 \%)$ & $224(46.3 \%)$ & $260(53.7 \%)$ \\
\hline Addis Ababa & $22(4.7 \%)$ & $447(95.3 \%)$ & $34(6.4 \%)$ & $497(93.6 \%)$ \\
\hline Dire Dawa & $60(12.9 \%)$ & $405(87.1 \%)$ & $169(34.9 \%)$ & $315(65.1 \%)$ \\
\hline
\end{tabular}

As it has shown in Table 2, the study has shown the effect of each variable on the women's autonomy in refusing risky sex in 2016. Among independent variables, two variables such as working status and residence had an insignificant association with women's autonomy in refusing risky sex.

However, women aged from 25-34 were less likely autonomous in refusing risky sex (AOR=.764; $95 \% \mathrm{Cl}=.605, .965)$, in comparison with women aged less than 24 years old. In comparison to illiterate women, the autonomy of women with primary, secondary, and higher educational status were $\mathrm{AOR}=1.607 ; 95 \% \mathrm{Cl}: 1.379,1.874, \mathrm{AOR}=2.208 ; 95 \% \mathrm{Cl}: 1.639,2.975$, and $\mathrm{AOR}=3.221 ; 95 \% \mathrm{Cl}: 1.647,6.300$. The autonomy of women from rich households was 1.523 times more likely higher in comparison to women from poor households (AOR=1.523; 95\% Cl:1.28,1.813). In the case of religion, when it was compared to Orthodox Christian women's autonomy except for Muslim women's autonomy (AOR=.799; $95 \% \mathrm{Cl} .652, .979)$, the autonomy of women from other stated religions was insignificant. Based on regions, the autonomy of women in Tigray, (AOR=2.938; 95\%Cl:2.025,4.263), Afar (AOR=1.497; 95\%Cl:1.111,2.017), Amhara (AOR=4.870; 95\%Cl: 3.388,7.000), Benishangul Gumuz (AOR=.568; 95\%Cl:.406,.796), SNNP (AOR=1.900; 95\%Cl:1.355,2.664), Harari (AOR=.516; 95\%Cl:.372,.716), and Addis Ababa $(A O R=3.809 ; 95 \% \mathrm{Cl}: 2.227,6.516)$ when compared with autonomy of women who resides Dire Dawa.

Table 2: Logistic regression analysis of associated factors on women autonomy in refusing risky sex (adjusted odds ratio) 


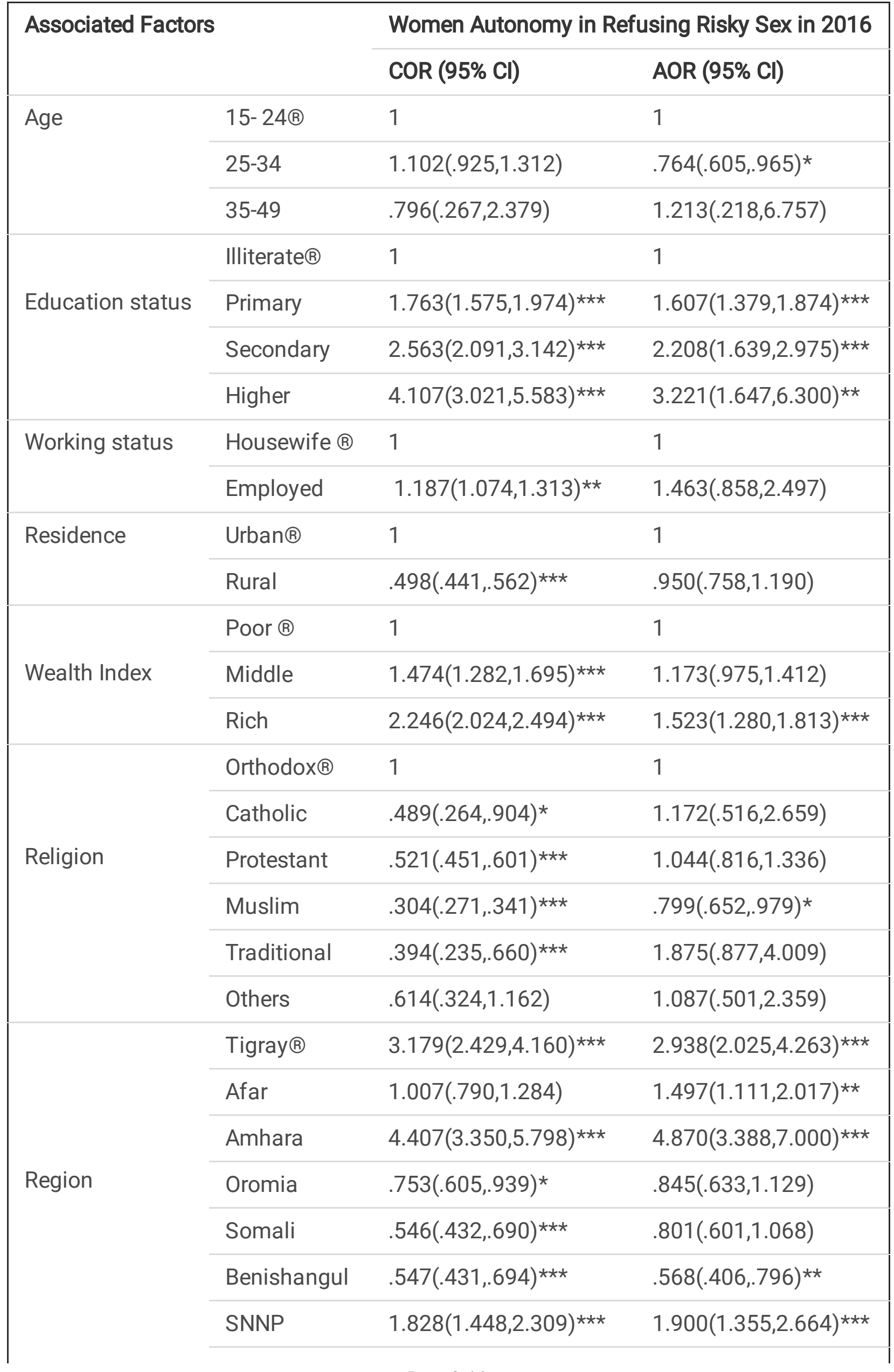




\begin{tabular}{|lll|} 
Gambela & $1.193(.924,1.539)$ & $.972(.669,1.410)$ \\
\hline Harari & $.623(.481, .806)^{\star \star \star}$ & $.516(.372, .716)^{\star \star \star}$ \\
\hline Addis Ababa & $7.842(5.286,11.636) \star \star \star$ & $3.809(2.227,6.516) \star \star \star$ \\
\hline Dire Dawa & 1 & 1 \\
\hline
\end{tabular}

Notes: ${ }^{\circledR}=$ Reference category; OR=odds ratio; $\mathrm{Cl}=$ confidence interval; ${ }^{*} \mathrm{p}<0.05 ;{ }^{* \star} \mathrm{p}<0.01 ;{ }^{* \star *} \mathrm{p}<0.001$.

\section{Discussion}

From 2011 to 2016, the autonomy of women in refusing risky sex was declined from $78.9 \%$ to $69.5 \%$ (by $9.4 \%)$. For this declination of the autonomy of women in refusing risky sex the possible justification might be because of the role of civil society organizations that work. In comparison with women aged less than 24 years old, older women (25-34 years old) were less likely autonomous in refusing risky sex. Similar to this study finding, on women autonomy in health care decision making $(15,21)$, household decision making (22), and on controlling and exercising their reproductive rights (23) age had a significant association. The finding of this study disclosed a direct relationship between women's status and autonomy in refusing risky sex. Other studies $(10,24)$ also found a positive association between women's autonomy with their educational status. Women's autonomy in refusing risky sex is positively associated with wealth index status. Correspondingly, other studies focused on household decisionmaking $(22,25)$. Similar to other studies $(26,27)$ finding, this study revealed Muslim women's autonomy. This might be because "it has been argued that Islam restricts women's freedom to a greater extent than other religions" (28).

\section{Conclusion And Recommendation}

The autonomy of women in refusing risky sex has declined from 2011 to 2016 . This infers that currently women are more victimized refusing risky sex than previously. Hence, possible interventions like empowering women shall be taken to save women from certain health problems of risky sexual behavior. Among independent variables: age, educational status, wealth index, and religion of women, as well as the current regions of women, were significantly associated with women's autonomy in refusing risky sex. The study finding revealed that women aged from 25-34, illiterate women, women from poor households, Muslim women, women from Benishangul Gumuz and Harari regions were less autonomous in refusing risky sex. Therefore, although declining autonomy of women in refusing risky sex is a serious problem in general, women aged from 25-34, illiterate women, women from poor households, Muslim women, women from Benishangul Gumuz and Harari regions in particular needs special attention of stakeholders such as non-governmental organizations, women, and children affairs office, and women's association. The roles of these stakeholders might focus on preventive and curative approaches. Holding open discussions among women each other and also providing training that can boost women's self- 
confidence as well as their understanding of women's rights and the impacts of risky sex are categorized under preventive technique. As a curative technique, arranging and providing legal support and guidance and counseling techniques are also essential roles.

\section{Declarations}

\section{Author's contributions}

MDA involved from the inception to design, acquisition of data, analysis, and interpretation, and drafting the manuscript, and edit the manuscript for the final submission. Ultimately, the author read and approved the final manuscript.

\section{Acknowledgment}

The author acknowledges Measure DHS for granting the data freely.

\section{Funding}

None

\section{Competing interests}

The author declares that he has no competing interests.

\section{Ethics approval}

This study is an analysis of a publicly available dataset where permission was obtained through registering with the DHS website and therefore no ethics approval was required

\section{Availability of data and materials}

The survey datasets used in this study were based on a publicly available dataset that is freely available at http://dhsprogram.com/data/dataset/Ethiopia_Standard-DHS_2016.cfm?flag=0. The released data is available without participants' identities. Approval was sought from MEASURE DHS/ICF International and permission was granted for this use.

\section{Author's information}

${ }^{1}$ Woldia University, Faculty of Social Sciences and Humanities, Department of Political Science and International Relations, P.O.Box 400, Woldia, Ethiopia.

\section{References}

1. Asrat A. Assessment of sexual risk behaviors of in-school youth: Effect of living arrangement of students; West Gojam zone, Amhara regional state, Ethiopia. American Journal of Health Research. 
2014;2(2):78-83.

2. Kassa GM, Degu G, Yitayew M, Misganaw W, Muche M, Demelash T, et al. Risky sexual behaviors and associated factors among Jiga high school and preparatory school students, Amhara Region, Ethiopia. International scholarly research notices. 2016;2016.

3. Perera UAP, Abeysena C. Prevalence and associated factors of risky sexual behaviors among undergraduate students in state universities of Western Province in Sri Lanka: a descriptive cross sectional study. Reproductive health. 2018;15(1):1-10.

4. Tadesse G. Women Empowerment and Their Reproductive Behaviour among Currently Married Women In Ethiopia. Addis Ababa University. 2018.

5. . Yomiyu Temesgen, Tsegaye Berkessa and Zakir Abdu Prevalence and Associated Factors of Risky Sexual Behavior among Students of Teachers Education College, in Mettu Town, South West Ethiopia Glob J Arch \& Anthropol 2018 7(3): GJAAMSID555712 0056.

6. Anteneh ZA. Prevalence and correlates of multiple sexual partnerships among private college students in Bahir Dar city, Northwest Ethiopia. Sci J Public Health. 2013;1(1):9-17.

7. Dyson T, Moore M. On kinship structure, female autonomy, and demographic behavior in India. Population and development review. 1983:35-60.

8. Banerjee P, Das SK. Autonomy: Beyond Kant and Hermeneutics: Anthem Press; 2008.

9. Organization WH. Global prevalence and incidence of selected curable sexually transmitted infections: overview and estimates. 2001.

10. Sougou N, Bassoum O, Faye A, Leye M. Women's autonomy in health decision-making and its effect on access to family planning services in Senegal in 2017: a propensity score analysis. BMC Public Health. 2020;20:1-9.

11. Birru TG, Molla M, Berhane Y, Wesen A, Chuko T. Determinants of Risky Sexual Behaviour among Preparatory School Students in Gurage Zone, SNNPR, Ethiopia (A Cross-Sectional School Based Study). Science. 2016;4(4):330-41.

12. CSA I. Central Statistical Agency (CSA)[Ethiopia] and ICF. Ethiopia Demographic and Health Survey 2016. Addis Ababa, Ethiopia, and Rockville, Maryland, USA: CSA and ICF; 2016. 2017.

13. Asfaw SJ, Asfaw KB. Prevalence of Modern Contraceptive Use and Associated Factors among Married Women at Quante Town, Gurage Zone Ethiopia, 2019. 2019.

14. Ghimire U. The effect of maternal health service utilization in early initiation of breastfeeding among Nepalese mothers. International breastfeeding journal. 2019;14(1):1-8.

15. Alemayehu M, Meskele M. Health care decision making autonomy of women from rural districts of Southern Ethiopia: a community based cross-sectional study. International journal of women's health. 2017;9:213.

16. Ebrahim NB, Atteraya MS. Women's Household Decision-Making and Intimate Partner Violence in Ethiopia. Academic journal of interdisciplinary studies. 2019;8(2):284-. 
17. Mekonnen A, Asrese K. Household decision making status of women in dabat district, north west Ethiopia, 2009 Gc. Science Journal of Public Health. 2014;2(2):111-8.

18. Tadele A, Tesfay A, Kebede A. Factors influencing decision-making power regarding reproductive health and rights among married women in Mettu rural district, south-west, Ethiopia. Reproductive health. 2019;16(1):1-9.

19. Peng C-YJ, Lee KL, Ingersoll GM. An introduction to logistic regression analysis and reporting. The journal of educational research. 2002;96(1):3-14.

20. Hosmer Jr DW, Lemeshow S, Sturdivant RX. Applied logistic regression: John Wiley \& Sons; 2013.

21. Osamor PE, Grady C. Women's autonomy in health care decision-making in developing countries: a synthesis of the literature. International journal of women's health. 2016;8:191.

22. Acharya DR, Bell JS, Simkhada P, Van Teijlingen ER, Regmi PR. Women's autonomy in household decision-making: a demographic study in Nepal. Reproductive health. 2010;7(1):1-12.

23. Biswas AK, Shovo T-E-A, Aich M, Mondal S. Women's autonomy and control to exercise reproductive rights: A sociological study from rural Bangladesh. Sage Open. 2017;7(2):2158244017709862.

24. Jejeebhoy SJ. Women's education, autonomy, and reproductive behaviour: Experience from developing countries. OUP Catalogue. 1995.

25. Ahmed M, Seid A. Does Women's Autonomy Matter on Attitude Towards Condom Use in Reducing Risk for HIV Infection Among Married Women in Ethiopia? HIV/AIDS (Auckland, NZ). 2020;12:489.

\section{Figures}

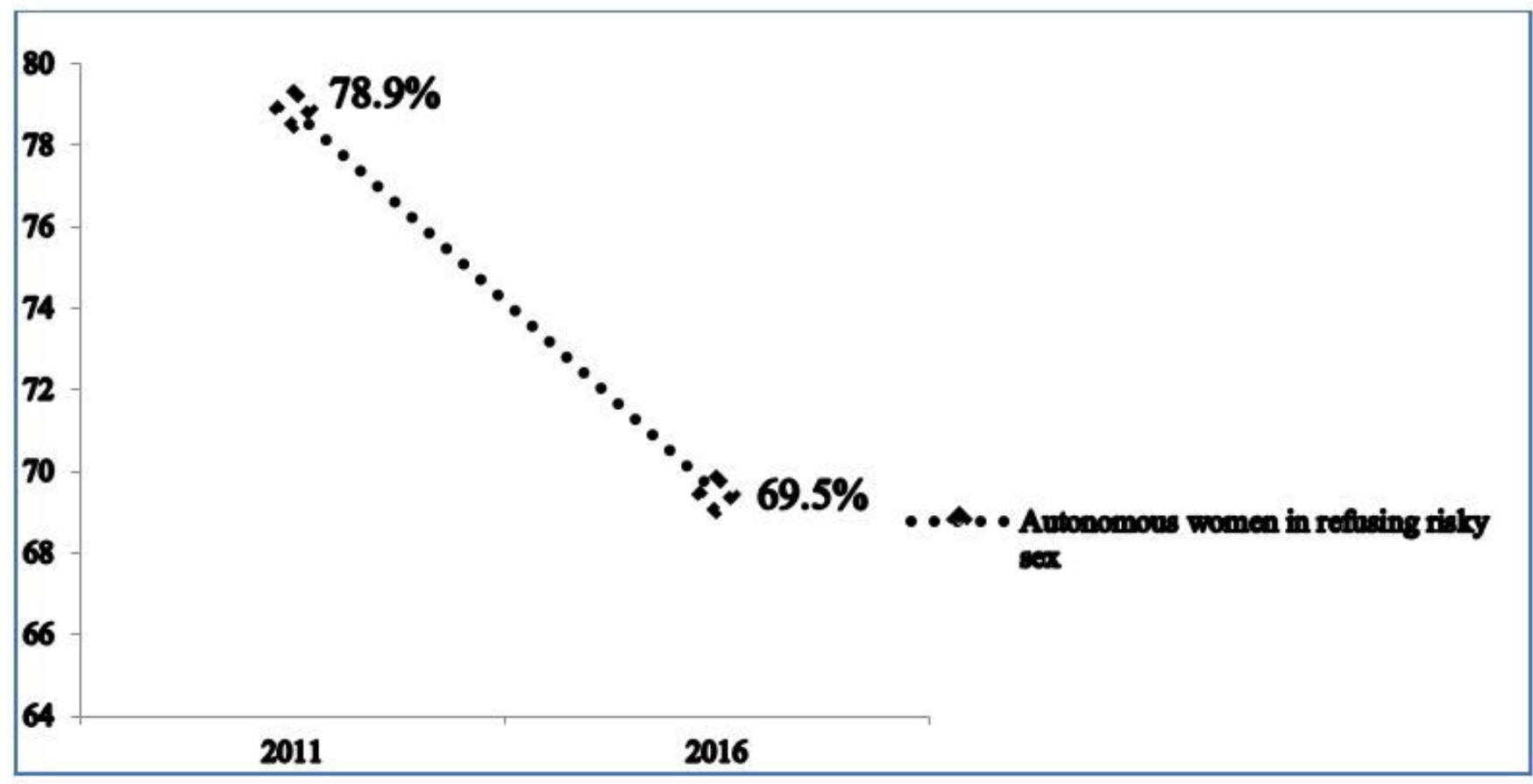


Figure 1

Women's autonomy in refusing risky sex 